\title{
The Importance of Agriculture in COVID-19 Pandemic Times in Puerto Rico
}

\author{
Javier E Pérez-Lafont* \\ Professor and Agricultural Economist, University of Puerto Rico at Utuado, USA
}

*Corresponding author: Javier E Pérez-Lafont, Professor and Agricultural

Economist, University of Puerto Rico at Utuado, USA.
Received Date: March 22, 2021

Published Date: March 26, 2021

\section{Opinion}

Agriculture is a fundamental activity for all economies. It is distinguished by being a supplier of food and fiber to society. The World Bank [1] states that this occupation is one of the most significant vehicles to reduce poverty and boost the well-being and food of a global population expected to reach 9.7 billion people by 2050 . Another unique fact shared by the World Bank on the importance of agriculture is that it accounts for one third of the world's gross domestic product.

Agriculture offers access to healthy foods. Imas [2] emphasizes that family farmers provide healthy, diversified and culturally adequate food. In addition, Imas (2020) states that this occupation has positive effects on the economy as they create agricultural and non-agricultural employment opportunities and promote the development of the country's economy. In addition, other notable aspects of this duty are the benefits that agriculture brings to the preservation of biodiversity and ecosystems to the extent that it is practiced in a sustainable and consonable manner with the environment.

FAO et al. [3] argues that the Latin American and Caribbean region has made significant progress in the direction of food health and safety over the years. However, the area has been significantly affected by low economic growth, the occurrence of unexpected events of nature, unsuitable ways of food production and consumption, as well as a rapid demographic transition. In parallel, Puerto Rico, an island located in the Caribbean, imports a large amount of the food it consumes which makes its population vulnerable to food insecurity. The Behavioral Risk Factor Surveillance System
(2015) survey conducted by the U.S. Department of Health notes the following aspects of the island's food fragility: it is estimated that $33.2 \%$ of the population 18 years of age or older in Puerto Rico exhibited food insecurity. $9.0 \%$ of the population 18 years of age or older were in the very low food security category. In addition, $21.7 \%$ of people indicated that in the last 12 months, there were times when fewer food had to be served or one of their daily meals stopped because of a lack of money.

Puerto Rico's pre-pandemic food weakness can be seen. If the effects of the Covid-19 are added to these important circumstances, the situation is more complicated for the island. FAO [4] states that the coronavirus disease pandemic has caused an unprecedented challenge for public health, food systems and the working world. The socioeconomic disorders that the present pandemic has unsealed are catastrophic. This circumstance has highlighted the weakness of food systems at the planetary level. It is therefore necessary to integrate immediate measures that promote health and safety in the areas of work particularly in the agricultural sector for conservation and recovery.

Puerto Rico and the world needs to face the following challenges among which can be noted: increase in the availability of labor, proliferate the number of farms in agricultural production, increase in the generational relief and the number of farmers. In Puerto Rico's case, the island should be aimed at improving their average age of the farm operators that is 60.6 years according to the Agricultural Census [5]; therefore, they need to reduce the digital lag since only $24 \%$ of farms in Puerto Rico have access to the Internet, this 
significant data was exposed by the Agricultural Census [6]. The development of long-term plans that provide for the health and safety of agricultural operators to maintain the stability of the country's agricultural production are essential to Puerto Rico and the world.

\section{Acknowledgement}

None.

\section{Conflict of Interest}

No conflict of interest.

\section{References}

1. (2020) Agriculture and Food. World Bank.

2. (2020) 2015-2018 Behavioral Risk Factor Surveillance System (BRFSS) Data from adults in 50 States, Puerto Rico, and the District of Columbia: People Aged 45 Years and Older. Cdc.gov.
3. FAO, PAHO, WFP, UNICEF (2019) Food security and nutrition overview in Latin America and the Caribbean 2019. Santiago 136 License: CC BYNC-SA 3.0 IGO.

4. FAO News (2020) Effects of COVID-19 on people's livelihoods, their health and our foodsystems. Fao.org.

5. Imas V (2020) Family Agriculture, STO and Post-Pandemic Economic Recovery. LET'S DECIDE-CADEP-OXFAM-EU.

6. United States, U.S. Department of Agriculture, National Agricultural Statistics Service (2020) 2017 Census of Agriculture. Washington, D.C., United States Department of Agriculture, AC-12-A-52, 1(52): 1-350. 